\title{
OPTIMAL LOCATION AND SIZING OF STORAGE UNITS IN A DRAINAGE SYSTEM
}

\author{
Maria C. Cunha ${ }^{1}$, João A. Zeferino ${ }^{1}$, Nuno E. Simões ${ }^{1}$, and Juan G. Saldarriaga ${ }^{2}$ \\ 1 - MARE, Department of Civil Engineering, University of Coimbra, Polo II, 3030-788, \\ Coimbra, Portugal. \\ 2 - CIACUA, Aqueduct and Sewage Research Center, Department of Civil and Environmental \\ Engineering, University of Los Andes, Bogotá, Colombia.
}

\begin{abstract}
Adapting urban stormwater drainage systems is essential to handling increased urbanization and climate change. Within an urban area, storage units are an efficient solution to reduce peak runoff, but their implementation involves complex decisions. This paper presents a novel optimization model for defining, in existing sewer drainage systems, the number of storage units, their location, size and the orifice dimensions. The orifice is used to reduce storage unit outflow regulating downstream flows. These components allow an integrated flow control and flooding reduction throughout the network. The desired solution should offer the lowest cost and try to avoid any major flooding impact. The model includes hydraulic, flood and capacity constraints and it is solved through a simulated annealing algorithm that calls upon a dynamic rainfall-runoff simulator for complete evaluation of each solution. The performance of the optimization model is assessed through a case study inspired by a real urban sewer network.
\end{abstract}

Keywords: storage unit; optimization model; simulated annealing; urban drainage system. 


\section{INTRODUCTION}

With urbanization, impermeable surfaces such as roofs and roads increase runoff peak, runoff volume, and decrease time to peak. In addition, the frequency of extreme rainfall events can be expected to increase with climate change (Butler and Davies, 2011, Karamouz et al., 2013, Kirshen et al., 2014, Andrés-Doménech et al., 2012). As a consequence, floods are likely to become more frequent, and better ways of managing flood water will be required. Adapting to these flood problems requires solutions such as sustainable urban drainage systems (Elliott and Trowsdale, 2007; Woods-Ballard et al., 2007; Butler and Davies, 2011; Fletcher et al., 2013; Fletcher et al., 2015), and one of the most efficient is to build storage facilities like retention, infiltration and/or detention basins. For existing drainage systems within an urban area, storage units (SUs) are an efficient and straightforward solution to reduce peak runoff (Kessler et al, 1991) and make it possible to keep existing conduits, prevent surcharging and reduce combined sewer overflow spills (Woods-Ballard et al., 2007).

The SUs used to enable sewer drainage systems to handle increased urban runoff need to be appropriately located and sized to mitigate risk to people and property, especially given the higher peak flow rates resulting from urbanization and climate change. As significant investment is required, a suitable compromise should be found between the economic and the technical, social and environmental aspects. The decision process for satisfying different requirements in a timely and precise manner entails highly complex tasks. When there are too many possible courses of action to be evaluated individually, this can be facilitated through optimization models.

Optimization models for flood reduction in drainage problems have often dealt either with the planning and design of storage facilities at watershed level or with the design of sewer systems. First attempts to mathematically model and optimize detention basin location problems were made by Doyle (1976), who used a mixed integer linear optimization model to evaluate alternative stormwater detentions in a watershed. The early nonlinear approaches have focused on cost efficient solutions for the capacity and release rates of single stormwater storage-release systems, using simplified solution methods such as graphical and numerical procedures (Nix and Heaney, 1988; Segarra, 1995). For storage facility planning and design at watershed level, optimization models have frequently been 
dealt with dynamic programming methods: Mays and Bedient (1982), aiming at cost minimization in the siting and sizing of detention basins for urban watersheds, extended by Bennett and Mays (1985) to include downstream channel reaches; Papa and Adams (1997), aiming at defining the optimal stormwater pond geometry in a watershed system, considering a specified pollution control level at the discharge points, extended in Behera et al. (1999), and adapted to a similar model in Rathnam et al. (2002); Travis and Mays (2008), aiming at finding the optimal siting and sizing of retention basins within a watershed. Yeh and Labadie (1997) applied successive reaching dynamic programming to the cost minimization of a watershed-level detention system and also used a multiobjective genetic algorithm to generate non-dominated solutions.

The early optimization models involving watershed-level planning and design problems were solved with the available optimization techniques at the expense of simplification in representing the hydraulic behavior and the number of variables considered. Modern heuristics have been used to solve optimization models including nonlinear functions and discrete variables, providing good solutions for a reasonable computing effort (Rothlauf, 2011). They are inspired by natural and physical analogies and iteratively search the solution space using intelligence-related concepts (Michalewicz and Fogel, 2004; Maier et al., 2014). Evolutionary algorithms have recently been applied to the detention pond geometry design problem (Park et al., 2012), the optimal location of best management practices at an integrated watershed-scale management problem (Zhen et al., 2004; Perez-Pedini et al., 2005; Artita et al., 2013), and to the optimal design of sewer systems and combined sewer overflows (Palumbo et al., 2014, Zimmer et al. 2015). Another population based algorithm, particle swarm optimization, has been shown to provide reliable results for the optimal design of detention ponds (Shamsudin et al., 2014). Recent optimization models have used simulated annealing (SA) algorithms in the optimal design of conduit size and slope in a sewer system (Karovic and Mays, 2014), and in the optimal design of detention basin systems on a watershed scale, without considering sewer system behavior (Oxley and Mays, 2014).

More recently, some optimization models have been presented for planning problems integrating the siting and sizing of SUs with the sewer drainage system, including the sewer system hydraulic behavior. Baek et al. (2015) used particle swarm optimization for location 
and sizing of storage tanks to manage combined sewer overflow spills. Cimorelli et al. (2015) used a genetic algorithm to solve an optimization model for positioning and sizing in-line parallel detention tanks consisting of large diameter conduits. Both approaches set out to design storage infrastructures that have to be large enough to retain the water and reduce peak discharges or avoid flooding. However, neither optimizes a flow control element, such as an orifice. The orifice has a smaller area than the downstream pipe, reducing the flow through it (Butler and Davis, 2011). Consequently, it allows efficient flow control throughout the entire network. Both Baek et al. (2015) and Cimorelli et al. (2015) used simple hydraulic models with the optimization model. Other modern heuristics applied to storage facility locating and sizing decision models in watershed-level and river basin related problems have been embedding commercial watershed simulation models (McEnery and Morris, 2012; Yazdi and Neyshabouri, 2012; Artita et al., 2013).

Siting and sizing SUs and their flow control elements in sewer drainage systems are relevant decisions that need to be made efficiently and carefully, and require new integrated approaches that are yet to be developed. This paper presents a novel optimization model for setting the number of SUs, their location and size, and their orifice size, in existing stormwater sewer systems. The orifice is used to regulate the outflow from the SU, to allow flow control and flood reduction over the entire network. The model presented is applied to an urban catchment that started suffering frequent floods in some areas. Its drainage system is composed of sewers and manholes that should be able to receive most of the runoff from a certain rainfall event so that surface water does not affect the local population. The SUs to be implemented are in-line buried structures with vertical walls, without infiltration and with an outlet orifice, that permit the temporary storage of water. The optimization model we presented is based on a single objective function subject to a set of hydraulic, flood and capacity constraints, and is solved through an SA algorithm. The SA algorithm is a heuristic method that is expected to provide useful solutions if designed to solve this type of model, as it has been used with remarkable results in several other hydraulic system planning models: groundwater (Dougherty and Marryott, 1991; Cunha 1999); water supply (Cunha and Sousa, 1999; Marques et al., 2015); wastewater (Zeferino et al., 2009; Andrade et al., 2013). SA is an algorithm that was first introduced by Kirkpatrick et al. (1983) and it can be designed to embed simulation models that mimic the behavior of 
complex systems. In optimization models where the hydraulic behavior of the drainage systems must be taken into account, such as in the integrated approach for location and sizing SUs with flow control, the values of the hydraulic variables have to be assessed through an appropriate hydraulic simulator.

The paper is organized as follows. In the next section, the optimization model is formulated and the method to solve it is described. The next two sections set out a case study where the model is applied and the results are presented and compared. The final section summarizes the work done and presents the main findings and conclusions.

\section{OPTIMIZATION APPROACH}

\subsection{Model Formulation}

Using the sets, decision variables, and parameters presented in Figure 1 and Table 1, the objective function and the various sets of constraints of the optimization model developed to represent the problem of the optimal location and sizing of SUs with flow control are given in separate subsections.

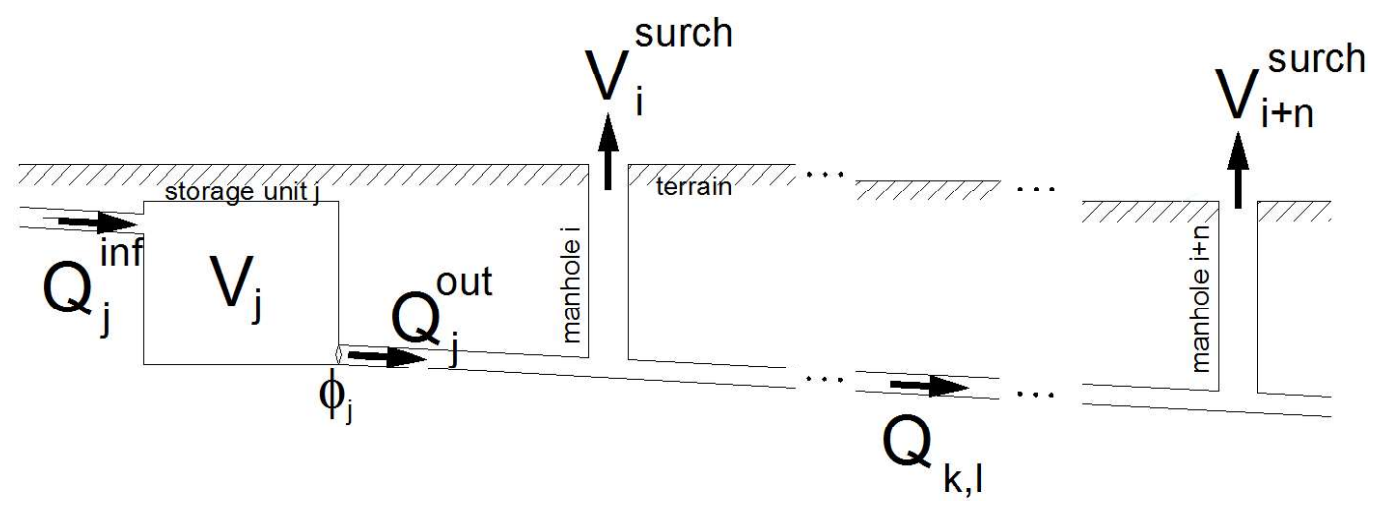

Figure 1 -Schematic figure of variables and parameters

Table 1 - Notation

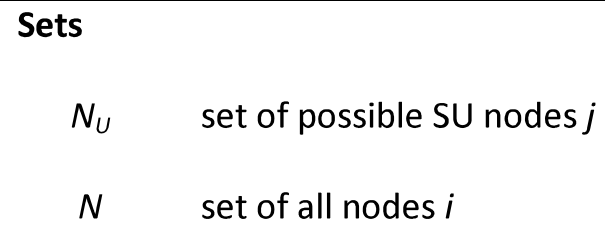


$y_{j} \quad$ binary variable that is one if there is an SU at node $j$ and zero otherwise

$V_{j} \quad$ volume of the SU at node $j$

$\phi_{j} \quad$ SU outlet (orifice) diameter at node $j$

$Q_{j}^{\text {out }} \quad$ outlet flow of the SU at node $j$

$Q_{j}^{\text {inf }} \quad$ inlet flow of the SU at node $j$

$V_{i}^{\text {surch }} \quad$ local flooding (surcharged) volume at node $i$

$Q_{k, l} \quad$ flow in conduit from node $k$ to node $I$

$Q^{\text {out }} \quad$ flow at the outfall node

\section{Objective function}

The objective function proposed for the optimization model consists of the minimization of the volumes of water related to flooding and SU storage for peak reduction. These water volumes can have a close correlation with the overall cost when that cannot be measured. The formulation of the objective function is as follows: 
$\operatorname{Min} \sum_{j \in N_{U}} V_{j}+\sum_{i \in N} \theta_{i} \cdot V_{i}^{\text {surch }}$

The first term of the objective function (1) corresponds to the sum of the volumes of all the SUs that are implemented in the sewer drainage system. The second term represents the weighted total flooding volumes, obtained by summing the weighted local flooding volumes occurring in all the nodes of the sewer network. These water volumes, together with a $\theta_{i}$ factor, can be used as a proxy in the absence of accurate economic estimations for the flooding damage. The $\theta_{i}$ factor allows decision makers to assign the importance given to the flooding impacts and provides a better understanding of the tradeoffs between the two terms. This coefficient can also be taken as a penalty applied to avoid flooding impacts.

\section{Hydraulic Constraints}

The optimization model needs to include a stormwater model, which predicts the behavior of the drainage system (Zoppou 2001). The Storm Water Management Model (SWMM) is a hydrology and hydraulic simulation model (Rossman, 2010; Gironás et al., 2010) that is widely applied in research and practice (Burger et al, 2014). It is used to evaluate the effects of each rainfall event. It quantifies rainfall-runoff processes and the hydraulic characteristics of water depth, flow in conduits and nodes, and flooding volumes. SWMM uses a nonlinear reservoir model in subcatchment areas to transform precipitation into runoff, and the SaintVenant equations to calculate the flow and water depth of this runoff in the sewer network (Rossman, 2010).

The maximum volume of water that is stored at an SU depends on the inlet flow and outlet flow. The orifice at the SU outlet allows the reduction of flow to the downstream part of the network. When the outlet flow is smaller than the inlet flow, the water is stored in the SU and returns to the conduits when they have spare capacity. The calculation varies according to whether the conduits/orifices are surcharged or not and this is taken into account through SWMM. It can be generally represented as:

$V_{j}=f\left(Q_{j}^{\text {inf }}, Q_{j}^{\text {out }}\right), j \in N_{U}$

Consequently, constraint (2) defines the necessary volume of SU at node $j$, resulting from the mass balance between the flow arriving at the SU and the amount of outflow that can reduce flooding downstream. 


\section{Flood and Capacity Constraints}

$$
\begin{aligned}
& \sum_{i \in N} V_{i}^{\text {surch }}\left(Q_{j}^{\text {inf }}, \phi_{j}\right) \leq V_{\max }^{\text {surch }} \quad, j \in N_{U} \\
& V_{i}^{\text {surch }}\left(Q_{j}^{\text {inf }}, \phi_{j}\right) \leq V_{\text {max }, i}^{\text {surch }} \quad, i \in N, j \in N_{U}
\end{aligned}
$$

Constraints (3) and (4) represent the flood constraints by specifying the limits on flooding that must be applied in the region or in each node, respectively. When conduits are surcharged water may reach the street level causing flooding. A decision maker can allow flooding up to a certain maximum value $\left(V_{\max }^{\text {surch }} \neq 0\right.$ or $\left.V_{\max , i}^{\text {surch }} \neq 0\right)$. If flooding is not allowed or does not occur, the flooding volume at node $i$ is zero $\left(V_{i}^{\text {surch }}=0\right)$. Flooding depends on the inlet flow of the upstream SUs and their respective orifice diameters, and it is evaluated through SWMM. When implementing upstream SUs with orifices, lower peak flows are obtained and thus flooding can be reduced to the specified value.

Usually, SUs are not meant to be implemented in all nodes, thus a limit number of SUs can be used.

$$
\sum_{j \in N_{U}} y_{j} \leq N S U
$$

Constraint (5) limits the number of SUs to a maximum of NSU.

Other important constraints are those that specify the minimum and maximum volume of the SUs and their orifice diameters.

$$
\begin{aligned}
& V_{j} \geq V_{\min , j} \cdot y_{j}, j \in N_{U} \\
& V_{j} \leq V_{\max , j} \cdot y_{j}, j \in N_{U} \\
& \phi_{j} \geq \phi_{\min , j} \cdot y_{j}, j \in N_{U} \\
& \phi_{j} \leq \phi_{\max , j} \cdot y_{j}, j \in N_{U}
\end{aligned}
$$

Constraints (6) and (7) ensure that there is a minimum volume limit to justify an SU at node $j$ (this constraint is used as a proxy to represent the effect of fixed construction costs and economies of scale) and that the volume must be lower than its pre-defined maximum capacity (according to the available space in that location). Constraints (8) and (9) guarantee 
that the orifice diameter at an SU node $j$ is larger than its pre-defined minimum value (very small diameters are likely to become clogged) and smaller than its pre-defined maximum value (that is, the diameter of the downstream conduit). The size of the orifice enables the outlet flow of SU to be controlled and thus all the flow downstream of that node, which supports the control of flooding at a downstream node $i$.

The outflow of the system can be set at a maximum value.

$Q^{\text {out }} \leq Q_{\max }^{\text {out }}, j \in N_{U}$

Constraint (10) limits the flow at the outfall node to a maximum of $Q_{\max }^{\text {out }}$.

\section{Domain constraints}

$y_{j} \in\{0,1\} \quad, \quad j \in N_{U}$

$V_{i}^{\text {surch }} \geq 0 \quad, i \in N$

Constraints (11) and (12) specify the domain of some variables.

\subsection{Model Solution}

To solve the model, a solution method based on an SA algorithm, which calls upon a hydraulic simulator whenever it is needed was implemented. OptSU, a user-friendly computer program written in Visual Basic, was developed to apply the optimization model, including the SA algorithm and the connection to the hydraulic simulator.

An SA is a physics-inspired algorithm that reproduces the annealing process in metallurgy (Kirkpatrick et al., 1983; Dowsland, 1993). This algorithm aims to mimic the annealing technique, which involves heating and then slowly cooling a metal in a controlled manner to improve its structural properties. A typical SA run consists of a number of successive (random) neighborhood moves in the problem space of solutions that are controlled through a set of parameters that govern the convergence of the algorithm. It starts with an initial solution, and progressively searches candidate solutions within the neighborhood, adopting new (the current) solutions until a good-quality solution is found (such as a lowcost solution in a cost-minimization problem).

In each solution evaluated by the SA algorithm, the hydraulic behavior of the sewer drainage network is simulated by the SWMM software. To facilitate the connection between 
the algorithm and the SWMM software, OptSU includes a SWMM toolkit (Iglesias and Martinez, 2014). OptSU can access and modify the network data in accordance with the SA algorithm, both for generating candidate solutions and defining current solutions during the model resolution. The basic steps of the model solution are shown in Figure 2.

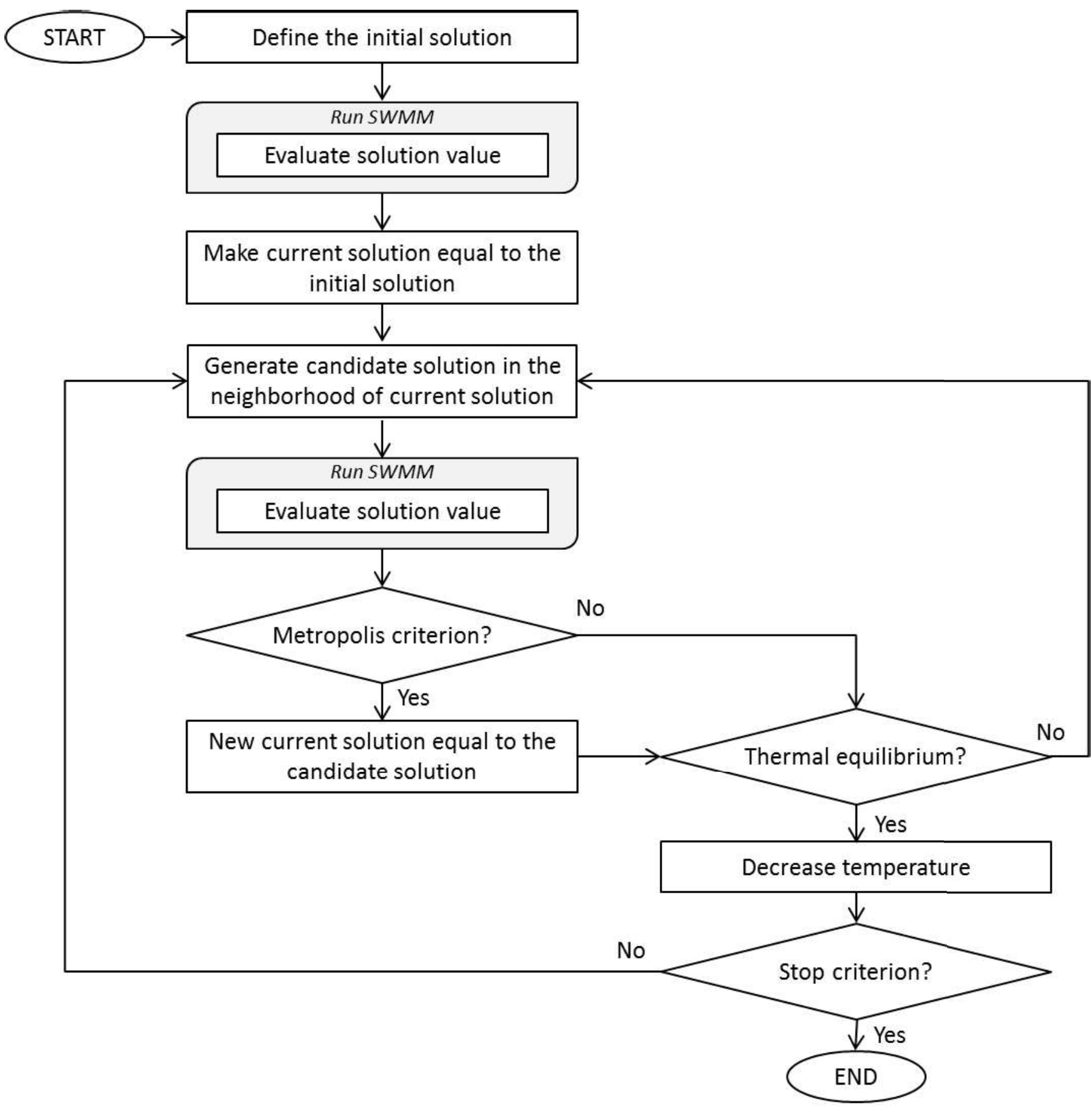

Figure 2 - Basic steps of the model solution in OptSU 
It starts by defining of an initial solution. The value of the initial solution is determined in terms of the model objective function and the compliance with its restrictions (by running SWMM), thus becoming the current solution. Then a candidate solution is generated within the neighborhood of the current solution and this, too, is evaluated. Their objective function values are compared and, depending on the temperature of the SA algorithm, the candidate solution can be accepted as the current solution according to the Metropolis criterion (see cooling schedule section). The temperature parameter of the SA algorithm helps to define which candidate solutions are accepted or rejected and it is decreased during the process according to a pre-defined cooling schedule, to improve the quality of the solutions. After a pre-defined number of solutions are generated at the same temperature, it is determined whether or not the thermal equilibrium has been reached (Aarts et al., 1997). Temperature should be decreased whenever this condition is met, and if not, the last current solution is retrieved. The stopping criterion is examined after a given number of temperature reductions. If the stopping criterion is not met the last current solution is retrieved, otherwise the algorithm ends and the best solution obtained during the search is assessed.

The definition of the initial solution, the definition of the neighborhood of a solution, and definition of the cooling schedule are given next. All the parameters of the algorithm and neighborhood moves were calibrated beforehand using a methodology such as that described by Cunha (1999) and Cunha and Sousa (1999).

\section{Initial Solution}

A preliminary study of the region where the optimization is to be applied should provide information about the possible locations and sizes of the SUs to be implemented. These potential SU sites are selected based on an analysis of the current flooding nodes, land availability, geographical conditions, and site-specific legal considerations. Regarding the possible capacity of the SUs, the minimum and maximum available storage volumes, $V_{\min }$ and $V_{\max }$ of constraints (6) and (7), respectively, must be set for each SU. The minimum and maximum diameters, $\Phi_{\min }$ and $\Phi_{\max }$ of constraints (8) and (9), respectively, must be set for the SUs' orifices. In addition, the height of each SU must be known so as to maintain the feasibility of the SU inlet conduit offset in each iteration. 
The initial solution is defined so that the SU locations and sizes are within the possible options and limits. This initial solution can be defined randomly (if it is feasible) because the SA algorithm is performed regardless its quality.

\section{Neighborhood of a solution}

The neighborhood of a solution consists of every solution that can be reached from it, resulting in a new candidate solution. A move within the neighborhood of a solution (neighborhood move) occurs at each iteration of the SA algorithm when a new candidate solution is generated (see Figure 2).

Each neighborhood move corresponds to a random modification at a possible SU location with three possible options: create an SU; remove an SU; or change the specifications of an SU (volume and orifice diameters - see Figure 1). Each option is given a different probability of occurring during the algorithm procedure. The probability of creating or removing an SU also depends on the number of nodes containing an SU. For instance, if all nodes contain an SU the probability of creating a new one is zero. A higher probability is given to the option of changing the specifications of an SU because this provides a more refined search of the neighborhood space of solutions. Moreover, when the specifications of an SU are changed, the amplitude of this neighborhood move is defined as a small interval within the minimum and maximum values of SU volumes and orifice diameters.

After a candidate solution has been modified, some corrections may have to be made to guarantee its feasibility. The volume and orifice diameter need to be within their minimum and maximum values (constraints 6 to 9). The number of SUs must be smaller than specified in constraint (5). In addition, if there is an SU in the solution, the inlet offset of its upstream conduits must be modified. When the candidate solution is infeasible in terms of the maximum total flooding (constraint 2) or the maximum local flooding (constraint 3), the algorithm penalizes its objective function value in such a way that it will not be an optimal solution; during the algorithm application this allows the neighborhood of this solution to be searched until new feasible solutions are obtained.

\section{Cooling Schedule}

The combined parameters that govern the convergence of the SA algorithm is called the cooling schedule. The temperature is one of the most important parameters of the 
algorithm to control the search procedure and as a great influence on the performance of the algorithm (Zeferino et al., 2009).

A candidate solution is accepted as the current solution according to a probability $p$ given by the Metropolis criterion: $p=\min \{1, \exp (-\Delta O F / T)\}$, where $\Delta O F$ is the change of the objective function value from the candidate solution to the current solution; $T$ is the temperature parameter. Initially, when the temperature is high, worse solutions are likely to be accepted. Although this can be seen like a drawback, it does mean that all the solution space is searched in an initial stage. As the temperature falls at a defined rate parameter of the SA, the acceptance of such moves will become increasingly rare. Occasionally accepting candidate solutions worse than the previous current solution helps the algorithm to avoid becoming trapped in a local optimum. When the temperature has dropped far enough and no improvements can be found, the best solution from the run is collected.

\section{CASE STUDY}

The proposed model was tested on a case study inspired by a real sewer drainage system in an urban area in Portugal. The urban region has a total area of 44 ha and encompasses 214 subcatchments. A total of 192 conduits with a length of approximately $6.5 \mathrm{~km}, 192$ junctions and 1 outfall were considered.

Figure 3 shows the case study area with the existing sewer drainage system. The concentration time of the catchment in the outfall section is approximately 30 minutes. Based on Portuguese IDF curves, the alternating block method (Chow et al., 1988) was used to derive a design storm with return period of 100 years, which simulates a high intensity rainfall event with associated flooding. It has duration of 2 hours and a maximum value of $161 \mathrm{~mm} / \mathrm{h}$.

The total flooding in the system nodes of the reference situation, with no SUs implemented, is $1696.6 \mathrm{~m}^{3}$. Figure 3 shows the location of flood volumes in each node. Most of the flooding problems occur at confluences of sub-branches and at slope variations. There are 3 nodes where flooding exceeds $100 \mathrm{~m}^{3}$ and the largest local flooding at a node is $623.9 \mathrm{~m}^{3}$. 


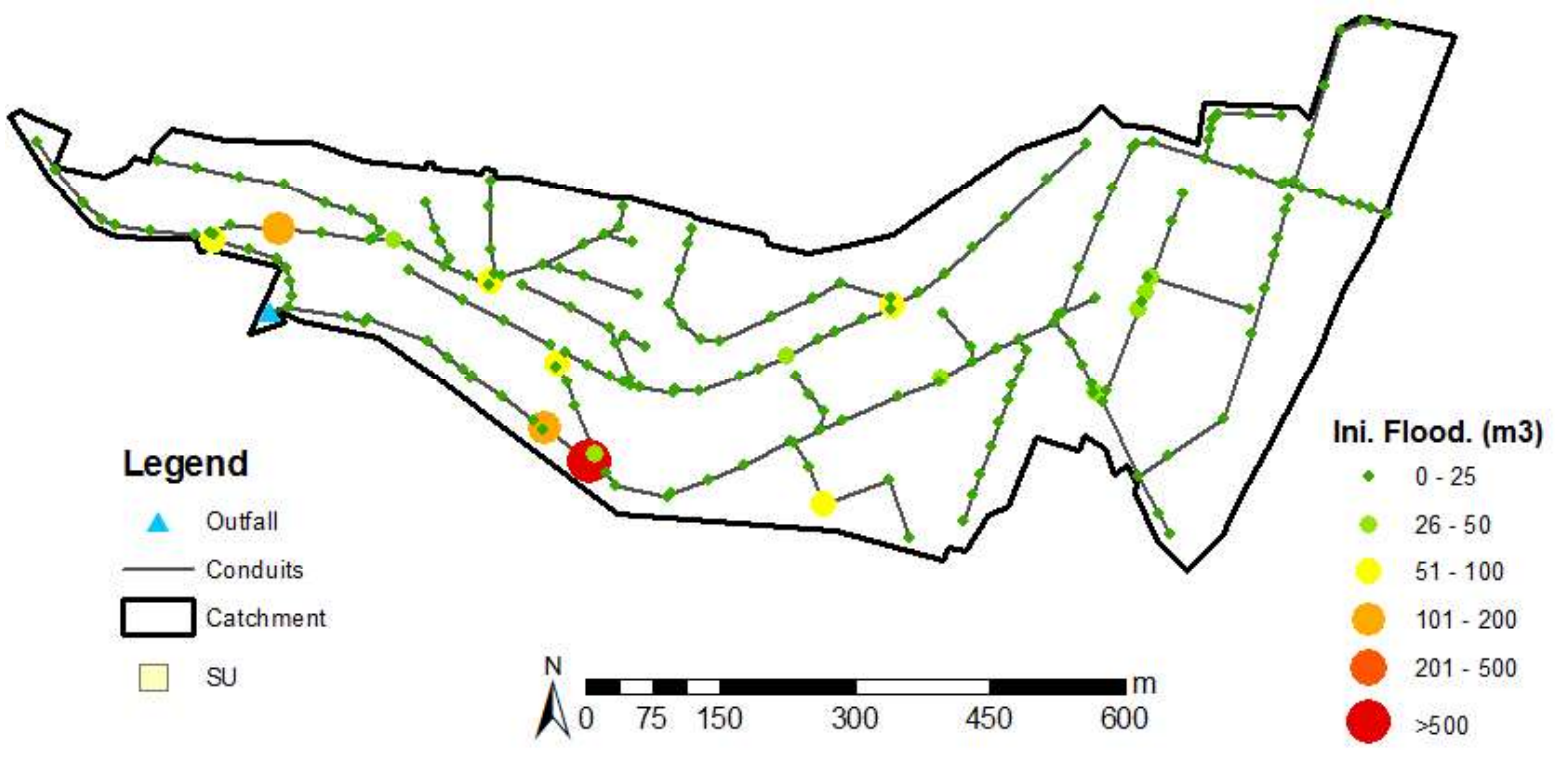

Figure 3 - Case Study and initial flooding volumes - reference situation

Theoretically, an SU could be considered for any point in the network and then the optimization model would provide a solution based on the specific characteristics of the problem. An evaluation of the existing sewer drainage system and the reference situation could reduce the number of potential SU locations. It can also help to reduce the complexity and computational demand of the problem.

In this demonstrative case study, after analyzing the morphology of the region, the available space and flooding, 17 possible sites for implementing SU were found (Figure 4). These sites are the viable nodes where the SUs could be built. The maximum occupancy area and thus the volumes of each SU were defined according to the land available at their sites. The minimum occupancy area at an SU site must be larger than $10 \%$ of the maximum area but no smaller than $25 \mathrm{~m}^{2}$, for reasons of economies of scale. The maximum diameter of the orifice downstream of an $\mathrm{SU}$ is that of the diameter of the downstream conduit cross section. The minimum diameter is $50 \%$ of the maximum one, and at least $200 \mathrm{~mm}$, to prevent clogging. These values are presented in Table 2. 


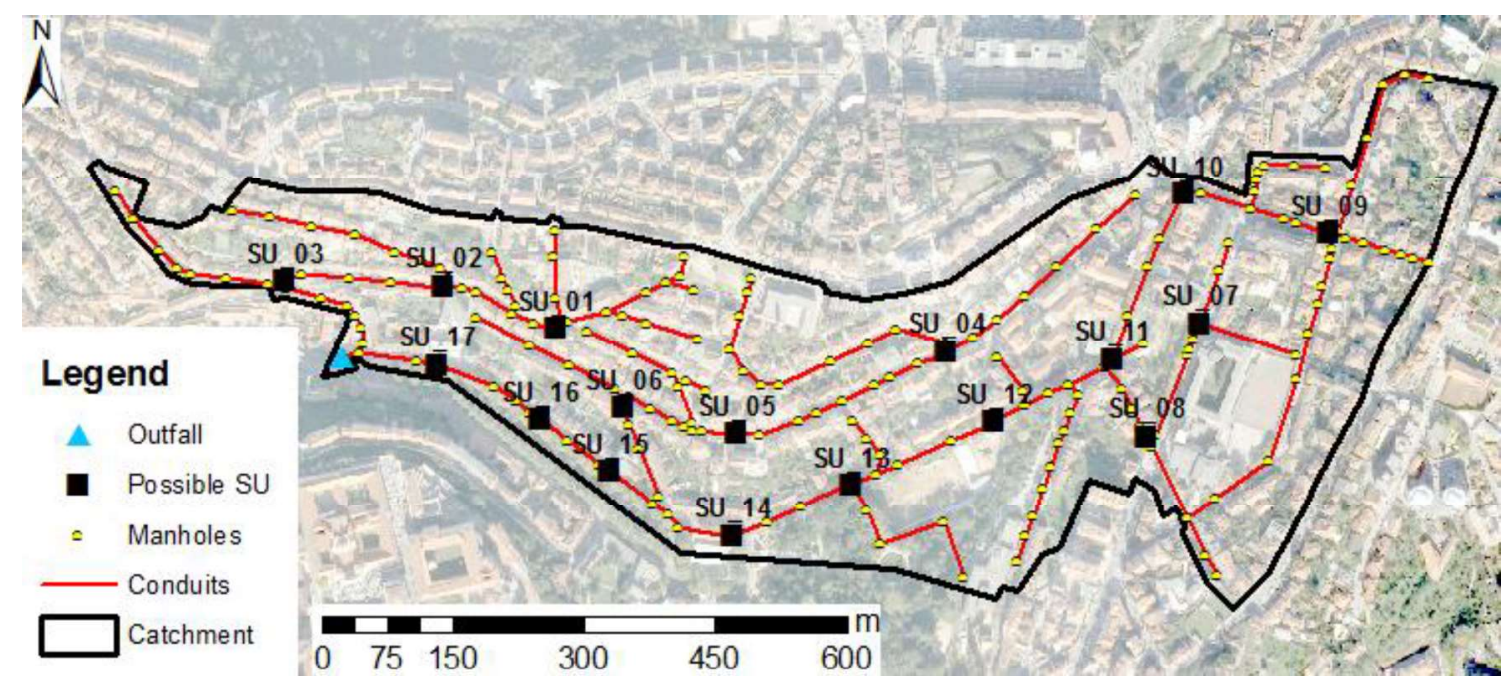

Figure 4-Case Study and possible SU locations

The sewer drainage system is a branched network that can be divided into four main branches (Figure 4). SU_01 to SU_03 are located in the northwest branch, which drains an area of 8 ha almost directly to the outfall. SU_04 to SU_06 are in the north branch (11 ha), and SU_07 to SU_14 are in the southeast branch, which is the longest and has the largest drainage area (23 ha). SU_15 to SU_17 are located in the south branch (2 ha). The largest local flooding occurs at the intersection where the north and southeast branches drain into the south branch. There are small flooding events in all catchments, though the other two nodes that suffer large flood volumes are in the northwest and south branches. 
Table 2 - Characteristics of possible SU locations

\begin{tabular}{|c|c|c|c|c|c|}
\hline \multirow[t]{2}{*}{ Node } & \multicolumn{2}{|c|}{$\begin{array}{c}\text { Occupancy area } \\
\left(\mathrm{m}^{2}\right)\end{array}$} & \multirow{2}{*}{$\begin{array}{l}\text { Depth } \\
(\mathrm{m})\end{array}$} & \multicolumn{2}{|c|}{$\begin{array}{c}\text { Orifice diameter } \\
(\mathrm{mm})\end{array}$} \\
\hline & min. & max. & & min. & $\max$ \\
\hline SU_01 & 25 & 250 & 2.50 & 200 & 300 \\
\hline SU_02 & 25 & 200 & 2.50 & 200 & 400 \\
\hline SU_03 & 25 & 250 & 2.50 & 200 & 400 \\
\hline SU_04 & 35 & 350 & 2.50 & 250 & 500 \\
\hline SU_05 & 40 & 400 & 2.50 & 250 & 500 \\
\hline SU_06 & 40 & 400 & 2.50 & 250 & 500 \\
\hline SU_07 & 30 & 300 & 2.50 & 200 & 350 \\
\hline SU_08 & 30 & 300 & 2.50 & 250 & 500 \\
\hline SU_09 & 25 & 150 & 1.50 & 200 & 400 \\
\hline SU_10 & 40 & 400 & 2.50 & 375 & 750 \\
\hline SU_11 & 35 & 350 & 2.50 & 375 & 750 \\
\hline SU_12 & 50 & 500 & 2.50 & 375 & 750 \\
\hline SU_13 & 50 & 500 & 3.00 & 525 & 1050 \\
\hline SU_14 & 100 & 1000 & 2.75 & 525 & 1050 \\
\hline SU_15 & 100 & 1000 & 2.50 & 400 & 800 \\
\hline SU_16 & 100 & 1000 & 2.50 & 400 & 800 \\
\hline SU_17 & 100 & 1000 & 2.50 & 600 & 1200 \\
\hline
\end{tabular}

In general, minimum flooding volume can be assumed, which can be other than zero if it does not create a significant impact. In this case study, if all the possible SUs are built with their maximum available volume, the total flooding will be around $160 \mathrm{~m}^{3}$, a reduction of $90 \%$, with largest local flooding of around $59 \mathrm{~m}^{3}$. This value is not zero because there is a limit on the SU volumes and there is flooding in some nodes that is not possible to be reduced as they are upstream of the potential SUs. .

Different examples were considered for the case study. These examples involve assigning different weighting to flood volumes, and varying the number of SUs and the number of flood volume constraint parameters.

\section{RESULTS}

\section{Sensitivity analysis of flooding weight and number of SUs}

OptSU was used to solve the optimization model. The case study is primarily tested for a set of different weightings for flooding to access the tradeoffs between implementing SUs and allowing a certain amount of flooding. The range of the flooding weighting covers a broad 
set of values from 0 (not important) to 100 (very important). The set of solutions obtained are compared for two alternative limits for the number of SUs to be implemented (NSU), set through constraint (5). No limits on the maximum total flooding and largest local flooding allowed in the region were considered. Figure 5 and Table 3 show the variation of the results in terms of SU volumes and total flooding, and largest local flooding, for different weighting values.

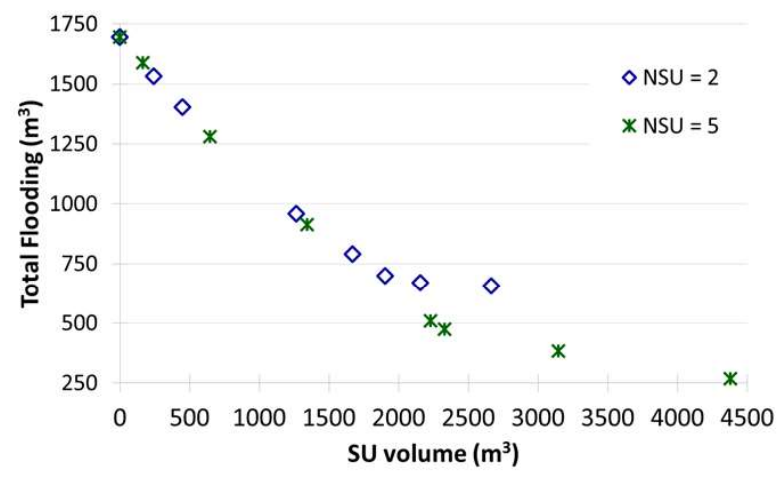

a)

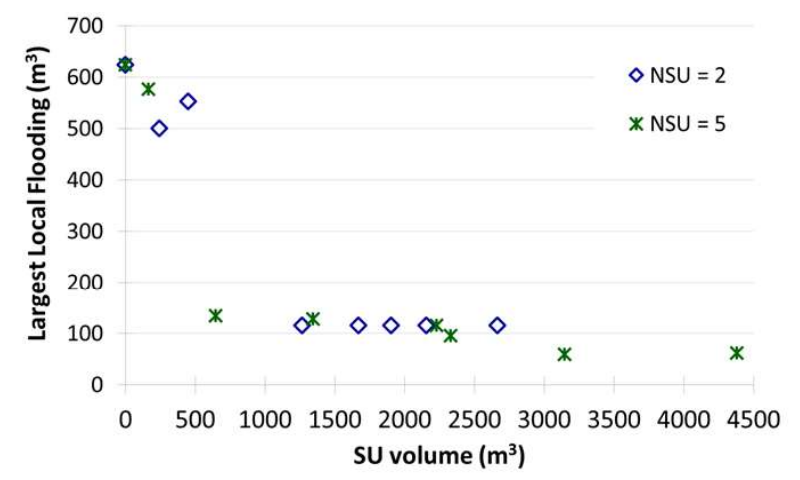

b)

Figure $5-a)$ solutions for different weightings in terms of total flooding; b) solutions for different weightings in terms of largest local flooding

Table 3 - Results for sensitivity analysis of flooding weighting and NSU

\begin{tabular}{cccccccccc}
\hline & NSU & $\mathbf{1}$ & $\mathbf{1 . 5}$ & $\mathbf{1 . 8}$ & $\mathbf{2}$ & $\mathbf{3}$ & $\mathbf{5}$ & $\mathbf{1 0}$ & $\mathbf{1 0 0}$ \\
\hline \multirow{2}{*}{ SU volume } & $\mathbf{2}$ & 0 & 242 & 448 & 1265 & 1668 & 1902 & 2155 & 2665 \\
& $\mathbf{5}$ & 0 & 164 & 644 & 1344 & 2229 & 2327 & 3145 & 4379 \\
\hline \multirow{2}{*}{ Total Flooding } & $\mathbf{2}$ & 1697 & 1531 & 1405 & 959 & 791 & 701 & 670 & 657 \\
& $\mathbf{5}$ & 1697 & 1589 & 1281 & 913 & 508 & 473 & 384 & 268 \\
\hline Largest Local & $\mathbf{2}$ & 624 & 501 & 553 & 116 & 116 & 116 & 116 & 116 \\
Flooding & $\mathbf{5}$ & 624 & 577 & 134 & 128 & 116 & 96 & 59 & 59 \\
\hline
\end{tabular}

As might be expected, there is a clear tradeoff between SU volumes and flood volumes, with both total flooding and largest local flooding decreasing as the volume of SUs increase. Indeed, the larger the weighting for flooding, the lower the total flooding. For $\theta=1$ the importance given to flooding is very low and solutions are the same as the reference situation, that is, with no SU implemented, either for $N S U=2$ or for $N S U=5$. Although the $\theta$ values were selected to cover a wide range of results, a noticeable rate of variation in both SU volumes and flooding was detected for $\theta$ around 1.8 and 2 (Figure 5). The same values of $\theta$ applied to NSU $=2$ and NSU $=5$ provided solutions with larger SU volumes, and thus lower flooding, the higher the number of SUs that was allowed. 
As larger volumes are ascribed to SUs, flooding reduction becomes less efficient, as shown in the chart in Figure 5 a), tending to a horizontal asymptote. The minimum possible flooding for the available SU capacities and corresponding to that asymptote should be more or less the same as provided by $\theta=100$, since such large importance given to flooding converts the problem to one of flooding minimization. For NSU $=5$ the total flooding reduction can be higher because the total capacity of the SUs is also larger. The results also show that when the minimum possible flooding is approached by $N S U=2$, similar values of SU volumes for NSU = 5 provided higher flooding reduction, as their SU volumes can be spread over different locations.

Regarding the largest local flooding shown in Figure $5 \mathrm{~b}$ ), increasing the SU volumes becomes ineffective after a certain capacity, as further local flooding reduction depends on SU location instead of their volume. Since for NSU $=5$ there are more potential locations to be served implementing SUs, the largest local flooding was reduced to $59 \mathrm{~m}^{3}$ whereas for $\mathrm{NSU}=2$ it did not fall below $116 \mathrm{~m}^{3}$. The largest local flooding need not necessarily decrease as $\theta$ increases because the objective function is aimed at minimizing the total flooding, and thus lower total flooding can be obtained at the expense of larger local flooding.

\section{Detailed analysis of five examples}

In this section a set of results is analyzed in more detail. The aim is to evaluate the effect of different constraints of the model and the relationships between the specificities of SUs and flooding reductions, including the different branches of the sewer drainage system where they are located.

An alternative to weighting the flooding volumes is to impose limits on the maximum total flooding and largest local flooding allowed in the region, set through constraints (3) and (4), respectively. Maximum values of $1000 \mathrm{~m}^{3}$ for total flooding or $100 \mathrm{~m}^{3}$ for local flooding are imposed, assuming that these will mitigate any larger negative impacts.

The solutions obtained with flooding limits and NSU $=2$ were analyzed in detail together with some of the previous solutions obtained using flooding weighting. All together they amount to five different examples for the case study, designed to mimic real problems and allow the performance of the proposed model to be evaluated. The examples are: 
- Example A: weighting for flooding $\theta_{i}=3$ for all nodes; no constraints on flood volume; maximum number of SUs (NSU) $=5$.

- Example B: weighting for flooding $\theta_{i}=3$ for all nodes; no constraints on flood volume; maximum number of SUs (NSU) $=2$.

- Example C: weighting for flooding $\theta_{i}=10$ for all nodes; no constraints on flood volume; maximum number of SUs (NSU) $=5$.

- Example D: weighting for flooding $\theta_{i}=0$; total flooding limit $=1000 \mathrm{~m}^{3}$; maximum number of SUs $(N S U)=2$.

- Example E: weighingt for flooding $\theta_{i}=0$; local flooding limit in each node $=100 \mathrm{~m}^{3}$; maximum number of SUs (NSU) $=2$.

The results for these examples were compared and analyzed thoroughly, focusing on the particularities of the examples, and are described below. The volumes of the SUs and their orifice diameters, and the total and maximum flooding compared with the reference situation, are presented in Table 4, for all examples. 
Table 4 - Results for the five examples

\begin{tabular}{|c|c|c|c|c|c|c|c|c|c|}
\hline & & & & & & & $\begin{array}{c}\text { Total SU } \\
\text { Volume } \\
\left(\mathrm{m}^{3}\right) \\
\end{array}$ & $\begin{array}{c}\text { Total } \\
\text { flooding } \\
\left(\mathrm{m}^{3}\right)\end{array}$ & $\begin{array}{c}\text { Max. Local } \\
\text { flooding } \\
\left(\mathrm{m}^{3}\right)\end{array}$ \\
\hline \multirow{3}{*}{ Reference } & SU number & - & - & - & - & - & \multirow{3}{*}{0.0} & \multirow{3}{*}{$\begin{array}{l}1696.6 \\
(100 \%)\end{array}$} & \multirow{3}{*}{$\begin{array}{c}623.9 \\
(100 \%)\end{array}$} \\
\hline & SU Vol. $\left(\mathrm{m}^{3}\right)$ & & & & & & & & \\
\hline & Orif. Diam. (m) & & & & & & & & \\
\hline \multirow{3}{*}{ Example A } & SU number & 4 & 6 & 7 & 8 & 13 & \multirow{3}{*}{2229.0} & \multirow{3}{*}{$\begin{array}{l}508.4 \\
(30 \%)\end{array}$} & \multirow{3}{*}{$\begin{array}{l}115.8 \\
(19 \%)\end{array}$} \\
\hline & SU Vol. $\left(\mathrm{m}^{3}\right)$ & 382.5 & 432.5 & 155.0 & 530.0 & 729.0 & & & \\
\hline & Orif. Diam. (m) & 0.284 & 0.341 & 0.238 & 0.328 & 0.586 & & & \\
\hline \multirow{3}{*}{ Example B } & SU number & 8 & 14 & - & - & - & \multirow{3}{*}{1667.8} & \multirow{3}{*}{$\begin{array}{l}791.4 \\
(47 \%)\end{array}$} & \multirow{3}{*}{$\begin{array}{l}115.8 \\
(19 \%)\end{array}$} \\
\hline & SU Vol. $\left(\mathrm{m}^{3}\right)$ & 482.5 & 1185.3 & & & & & & \\
\hline & Orif. Diam. (m) & 0.347 & 0.586 & & & & & & \\
\hline \multirow{3}{*}{ Example C } & SU number & 2 & 4 & 6 & 7 & 12 & \multirow{3}{*}{3145.0} & \multirow{3}{*}{$\begin{array}{l}384.4 \\
(23 \%)\end{array}$} & \multirow{3}{*}{$\begin{array}{c}59.3 \\
(10 \%)\end{array}$} \\
\hline & SU Vol. $\left(\mathrm{m}^{3}\right)$ & 480.0 & 707.5 & 367.5 & 347.5 & 1242.5 & & & \\
\hline & Orif. Diam. (m) & 0.217 & 0.260 & 0.325 & 0.200 & 0.510 & & & \\
\hline \multirow{3}{*}{ Example D } & SU number & 7 & 12 & - & - & - & \multirow{3}{*}{1217.5} & \multirow{3}{*}{$\begin{array}{l}990.0 \\
(58 \%)\end{array}$} & \multirow{3}{*}{$\begin{array}{l}115.8 \\
(19 \%)\end{array}$} \\
\hline & SU Vol. $\left(\mathrm{m}^{3}\right)$ & 165.0 & 1052.5 & & & & & & \\
\hline & Orif. Diam. (m) & 0.218 & 0.531 & & & & & & \\
\hline \multirow{3}{*}{ Example E } & SU number & 2 & 12 & - & - & - & \multirow{3}{*}{1327.5} & \multirow{3}{*}{$\begin{array}{l}997.2 \\
(59 \%)\end{array}$} & \multirow{3}{*}{$\begin{array}{c}90.7 \\
(15 \%)\end{array}$} \\
\hline & SU Vol. $\left(\mathrm{m}^{3}\right)$ & 77.5 & 1250.0 & & & & & & \\
\hline & Orif. Diam. (m) & 0.240 & 0.511 & & & & & & \\
\hline
\end{tabular}

As expected, all five examples led to a lower flooding volume relative to the reference solution (the relative percentage is shown in Table 4). The number of SUs implemented is equal to the maximum number allowed, for all examples. When five SUs are implemented, lower flooding volumes are obtained but a greater storage volume is used since, as mentioned previously, the same $\theta$ is more flooding averse for larger NSU. In addition, the five SUs are sited in several branches, thus allowing lower maximum local flooding volumes. When only two SUs are implemented, the branches where they are located varies depending on the restrictions, and it is more difficult to reduce flooding in all branches. In most of the five examples, locations SU_12 or SU_7 are selected. Both these are in the southeast branch, which drains approximately half of the catchment area directly into the branch where most flooding occurs and which therefore contains at least one selected SU, for all examples.

In Example A (Figure 6), the weighting for flooding is $\theta_{i}=3$ for all nodes, there are no flooding volume limits, and it is possible to implement a maximum of five SUs in any 
possible location (restricted to the maximum storage volume in each SU). The best solution obtained creates five SUs (SU_04, SU_06, SU_07, SU_08, and SU_13), with volumes ranging from $155.0 \mathrm{~m}^{3}$ to $729.0 \mathrm{~m}^{3}$, making a total storage volume of $2229.0 \mathrm{~m}^{3}$. These are the SU volumes that will only be filled with water at the most critical times. All the SUs have a small orifice to decrease the outlet flow. SU_04 and SU_06 are in the north branch and SU_07, SU_08 and SU_13 are in the southeast branch of the region. This results in a decrease in largest local flooding, which happens in the south branch (downstream of the north and southeast branches) from $623.9 \mathrm{~m}^{3}$ in the reference situation to $115.8 \mathrm{~m}^{3}$. This new local maximum flooding occurs in the northwest branch where there are no SUs, thus the flooding volumes of the reference situation are maintained (compare with the northwest branch in Figures 3 and 5). Regarding the total flooding volume, this decreases around $70 \%$, to $508.4 \mathrm{~m}^{3}$.

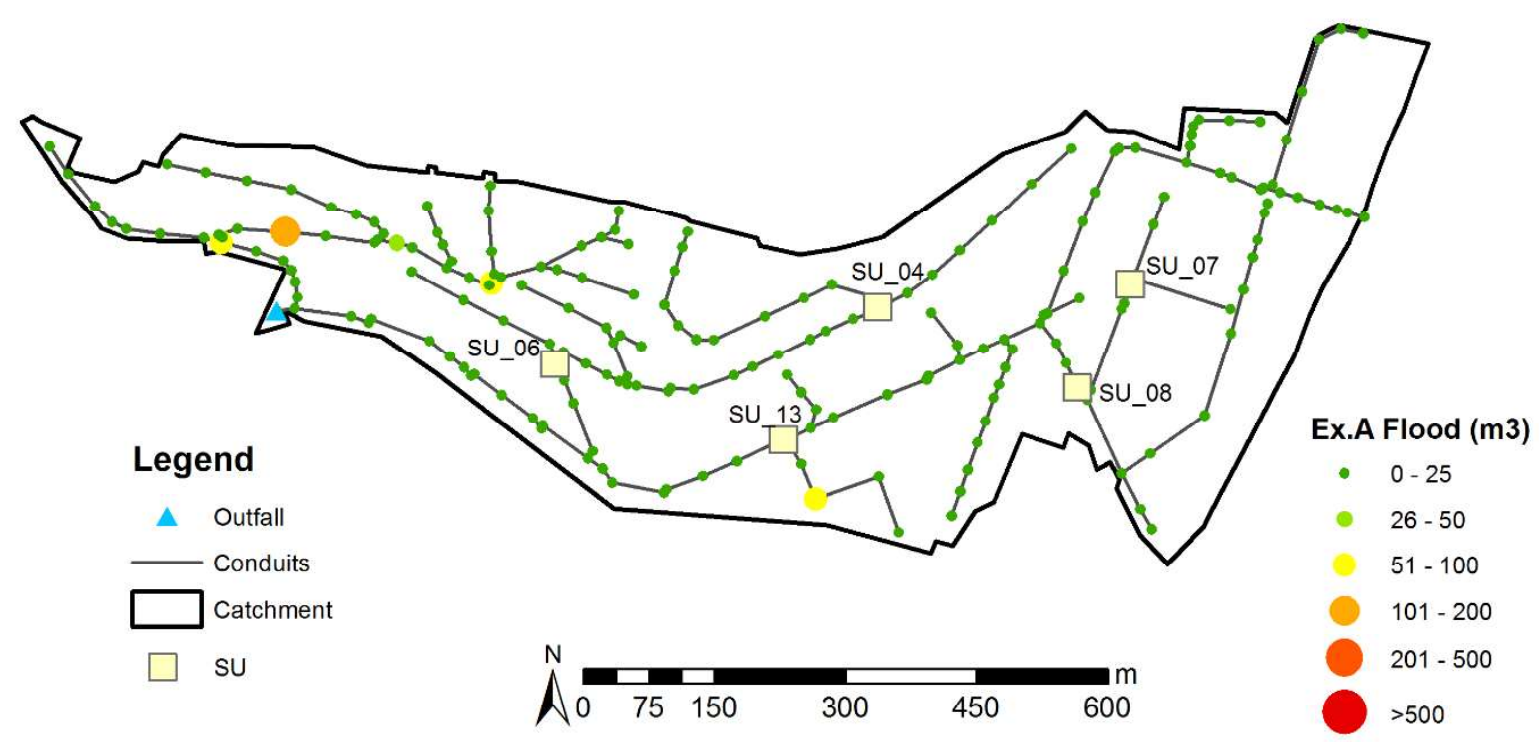

Figure 6 - Flooding volumes for the best solution in Example A

In Example B (Figure 7), the weighting for flooding is $\theta_{i}=3$ for all nodes, there are no flooding volume limits, and it is possible to implement only a maximum of two SUs in any possible location (in addition to the restriction on the maximum storage volume in each SU). The best solution obtained creates two SUs (SU_08 and SU_14), with volumes of $482.5 \mathrm{~m}^{3}$ and $1185.3 \mathrm{~m}^{3}$. SU_08 is used in both Example A and Example B. Example B selects SU_14, which is in the same street as SU_13 (selected in Example A), although SU_14 has a larger volume in Example B. The total storage volume is $1667.8 \mathrm{~m}^{3}$, which is $25 \%$ less than for Example A. The two SUs are located in the southeast branch, which is the largest and has a 
greater direct impact on overall flooding. Consequently, the largest local flooding is in the same location as in Example A, because it occurs in a branch that has no SU in either example. The total flooding volume falls to $791.4 \mathrm{~m}^{3}$, which is larger than for Example $A$ and is a $53 \%$ reduction relative to the reference situation. Although SU_08 and SU_14 could be larger (in terms of their maximum capacity), they are big enough to reduce flooding in their downstream nodes to a residual level (not zero due to the contribution of the north branch to those downstream nodes).

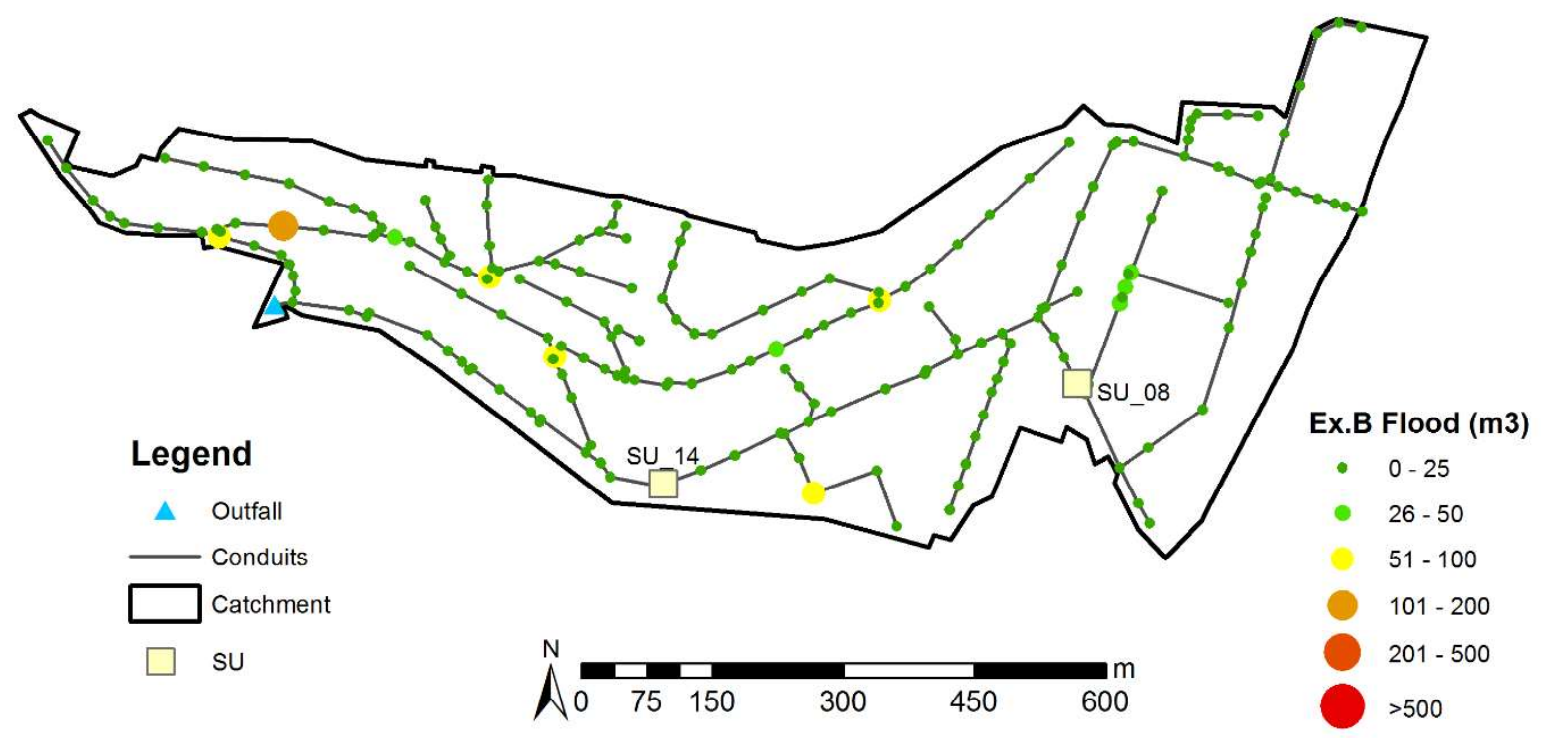

Figure 7 - Flooding volumes for the best solution in Example B

In Example C (Figure 8), the weighting for flooding is high at $\theta_{i}=10$ for all nodes, there are no flooding volume limits, and it is possible to implement a maximum of five SUs in any possible location (restricted to the maximum storage volume in each $\mathrm{SU}$ ). It is similar to Example A, but with a higher weighting for flooding. The best solution obtained creates five SUs (SU_02, SU_04, SU_06, SU_07 and SU_12), with volumes from $347.5 \mathrm{~m}^{3}$ to $1242.5 \mathrm{~m}^{3}$. Their orifices have diameters near the minimum allowed, indicating that a large amount of water is being stored. The resulting total storage volume of $3145.0 \mathrm{~m}^{3}$ is the highest of all five examples. Hence, it has the lowest values for both the total flooding ( $384.4 \mathrm{~m}^{3}$ ) and the largest local flooding $\left(59.3 \mathrm{~m}^{3}\right)$, representing a $77 \%$ and a $90 \%$ reduction compared with the reference situation, respectively. The Example C solution has a $41 \%$ larger total SU volume than Example A. Because flooding has more weighting in this model than in Example $A$, besides implementing SUs in the southeast and north branches, Example C also sites an SU 
in the northwest branch upstream of a node where significant flooding occurs in the reference situation. Thus, the largest local flooding is $49 \%$ lower than for Example A.

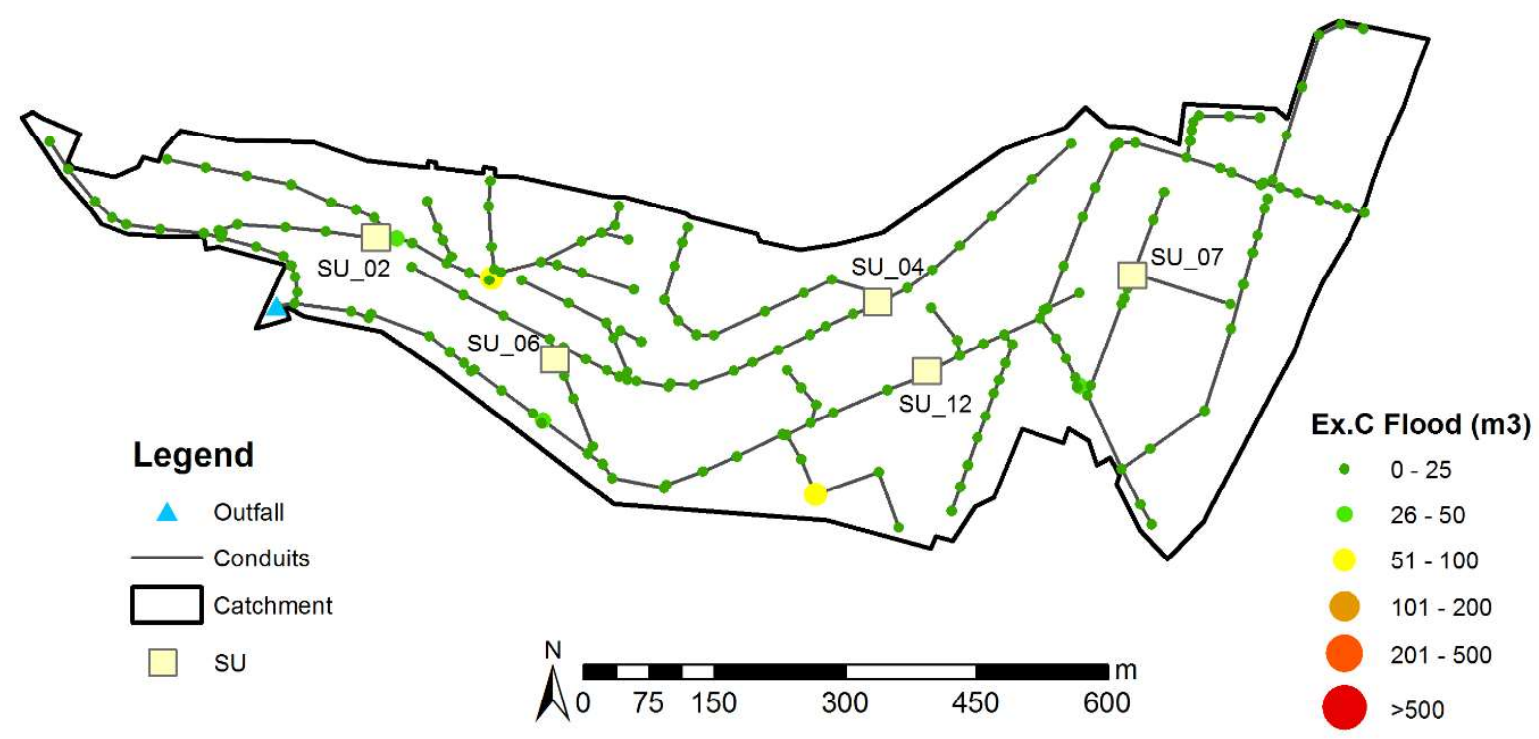

Figure 8 - Flooding volumes for the best solution in Example $\mathrm{C}$

For Example D (Figure 9), there is no weighting for flooding, but a total flood limit of 1000.0 $\mathrm{m}^{3}$ is considered. The maximum number of SUs is 2 . Therefore, the best solution obtained creates two SUs (SU_07 and SU_12) with a total storage volume of $1217.5 \mathrm{~m}^{3}$, which is the lowest of all five examples. The total flooding is therefore $990.0 \mathrm{~m}^{3}$. This figure guarantees the limit assumed by the total flooding constraint. Regarding the largest local flooding, this is reduced from the $623.9 \mathrm{~m}^{3}$ occurring in the south branch to $115.8 \mathrm{~m}^{3}$, which occurs in the northwest branch, similar to Examples A and B. As in Example B, the two SUs are located in the southeast branch, but in Example D they are located upstream of the SU sites in Example B, since their smaller storage capacity is enough to guarantee the assumed flood limit. In Example $D$ the flooding is limited by a maximum value, while in Example $B$ it is conditioned by a weighting. Therefore, the total flooding volume is $27 \%$ lower in Example $B$ at the expense of an extra $25 \%$ storage volume. In fact, in Example $D$ the model has no advantage in reducing flooding to less than $1000 \mathrm{~m}^{3}$. 


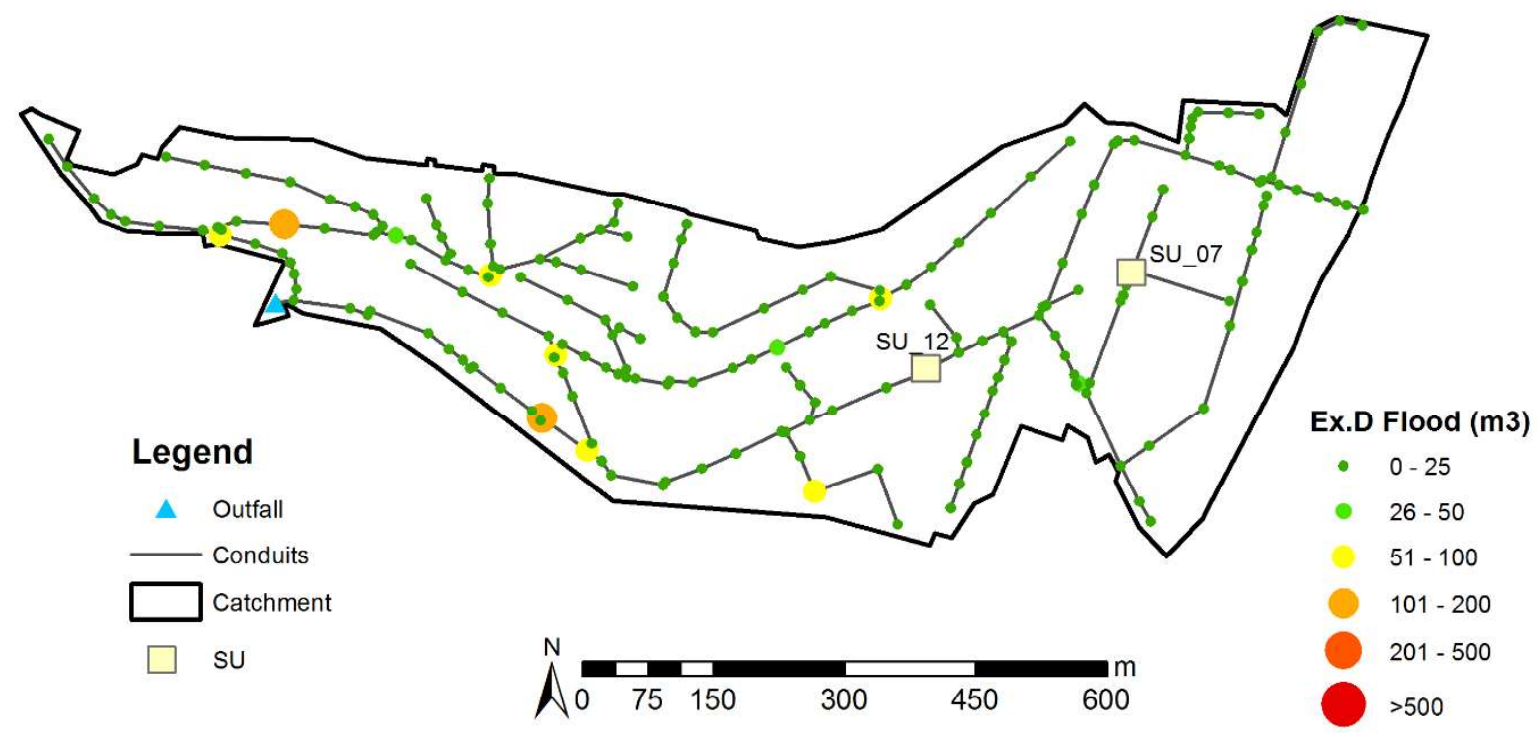

Figure 9 - Flooding volumes for the best solution in Example D

For Example E (Figure 10), there is no weighting for flooding, but a flood limit of $100 \mathrm{~m}^{3}$ is assumed for each node. The maximum number of SUs is 2 . The best solution obtained creates two SUs (SU_02 and SU_12) with a total storage volume of $1327.5 \mathrm{~m}^{3}$, and one of them is the largest SU implemented in any of the examples (SU_12 with $1250.0 \mathrm{~m}^{3}$, which is the maximum capacity). Nevertheless, the total flooding volume is the highest $\left(997.2 \mathrm{~m}^{3}\right)$, but thanks to the local flooding constraint the largest local flooding volume is $90.7 \mathrm{~m}^{3}$, which is a reduction of $85 \%$ relative to the reference situation. Comparing Example $E$ and Example $D$, the different flooding limitations lead to similar but slightly different results. SU_12 is selected in both examples, but Example D has both SUs in the southeast branch. Due to the local flooding limitation, Example E has slightly larger total flooding, but its largest local flooding is lower at the expense of a 9\% larger SU storage volume. 


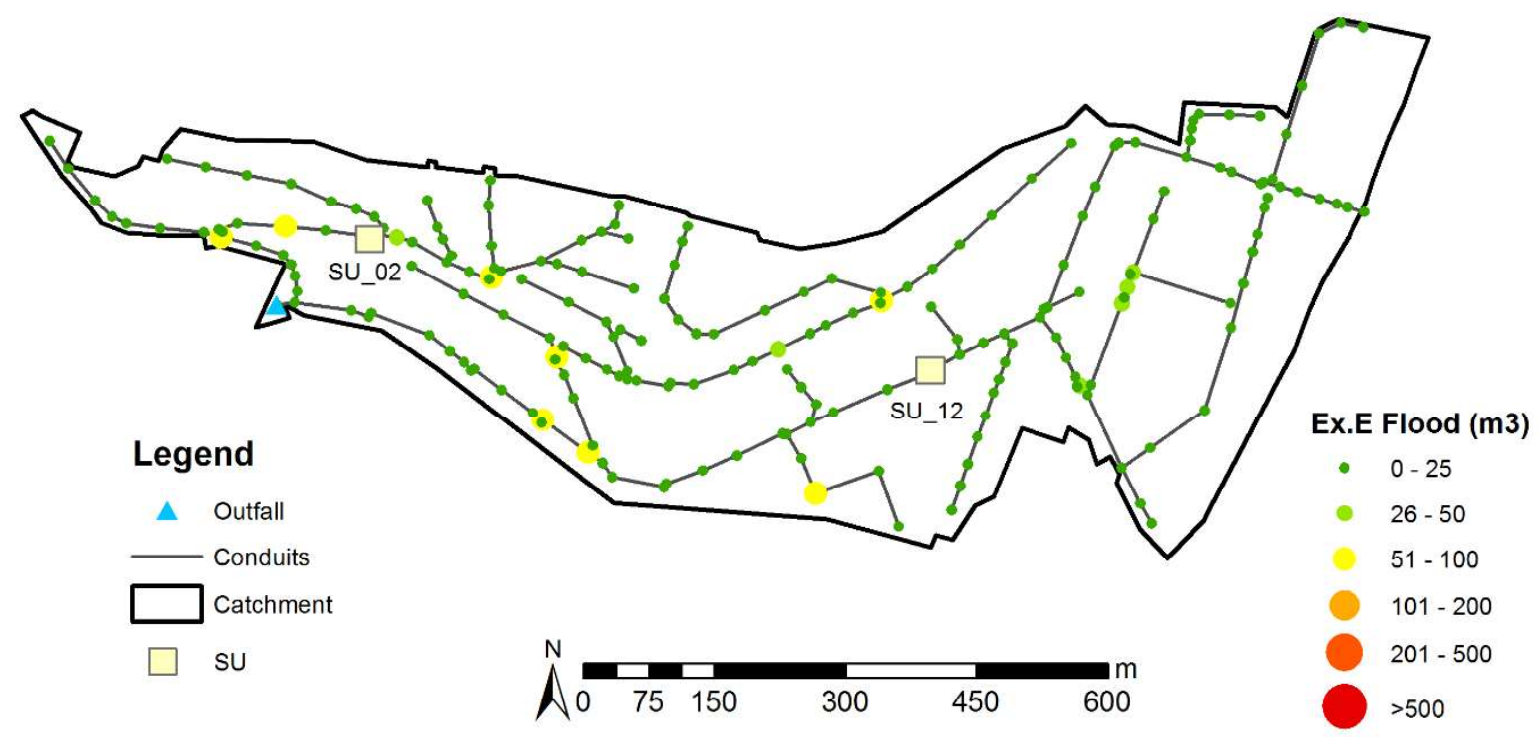

Figure 10 - Flooding volumes for the best solution in Example $E$

Generally, the model tends to select SUs in the southeast branch, which is the longest, has the largest drainage area, and is located upstream of some nodes with considerable flooding volumes. When more than two SUs were used, the north and northwest branches were also selected, to reduce flooding there. The south branch does not have an SU in any example because most of flooding occurs in its upstream node and branches. Locating an SU in the upstream branches solves the flooding problems more efficiently. The size of the SUs is sensitive as different number of SUs or flooding limits require different volumes of waters to be stored in each branch.

Figure 11 and Figure 12 show flows in a conduit in the reference situation, without any SU and orifice, and after the construction of an SU and its orifice, for Example $C$ and Example $D$, respectively. They also show the water level after those SUs are built. This represents the hydraulic impact of the construction of an SU. Because of the orifice at the SU outlet, the volume of water is stored in the SU and the peak flow downstream of the SU is constrained and decreases, thereby reducing flooding. In both figures the maximum depth of the SU is used to store water, meaning an accurate design volume is obtained in the optimization model. This occurs not only in these cases but for all the SUs implemented in all examples tested. 


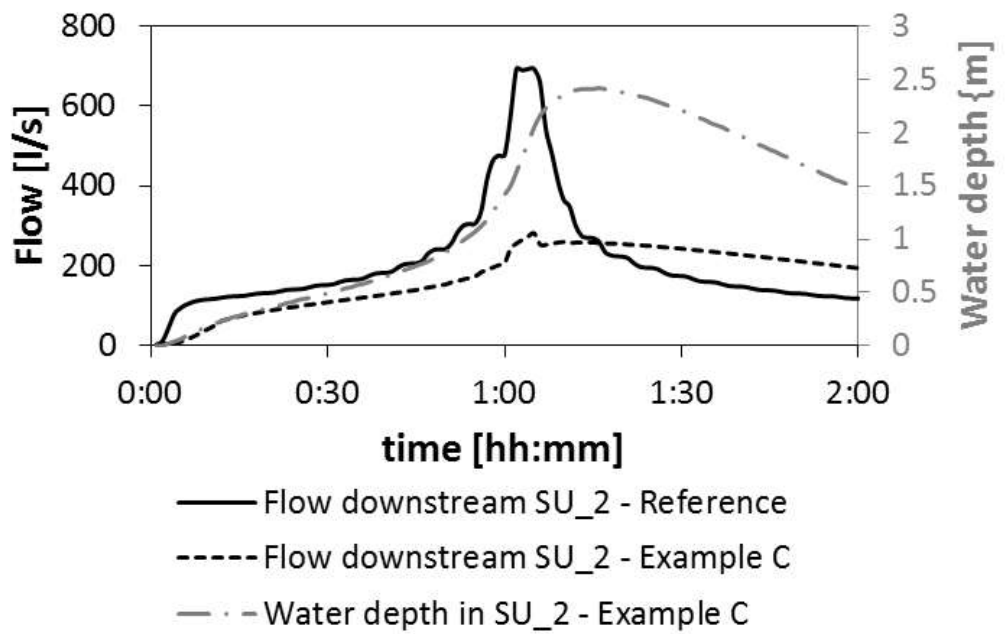

Figure 11 - Hydraulic impact of SU_2 in Example C.

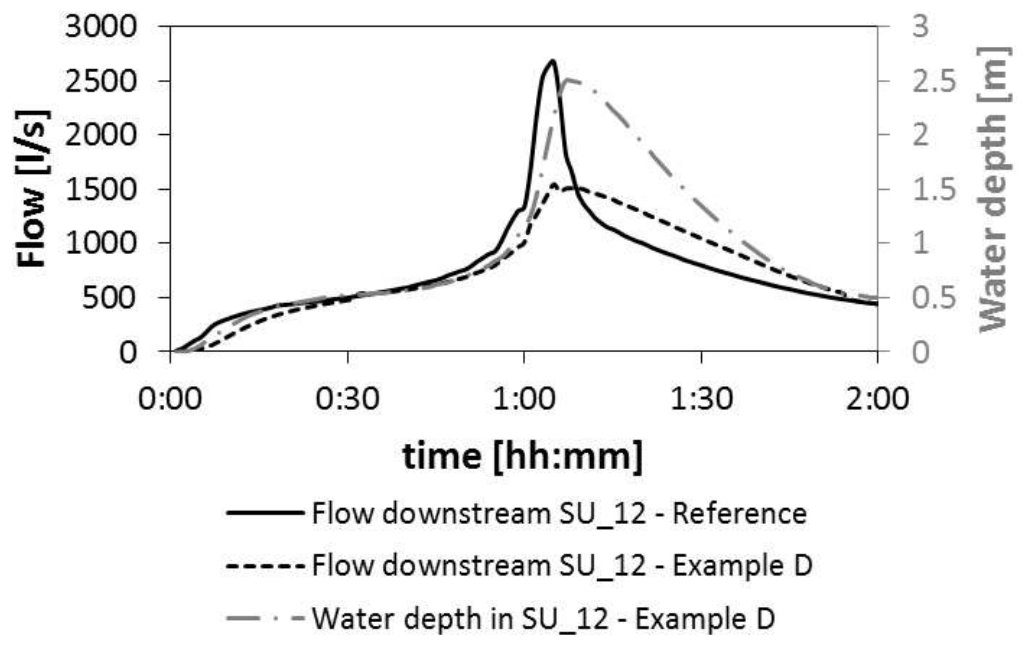

Figure 12 - Hydraulic impact of SU_12 in Example D.

\section{CONCLUSION}

The increase of urbanization and climate change are making floods more frequent and seriously affecting cities. Therefore, new flood management practices are being applied. Storage infrastructure elements are effective solutions for peak flow reduction and flood control in existing sewer drainage systems, but their location, dimensions and flow control capabilities can strongly affect their efficiency. Because of this aspect and the large number of possible alternatives, the constraints to be met, and the high investment involved, an optimization model should be used to efficiently implement new solutions, taking into account all the criteria and their interactions. 
A novel optimization model has been described that defines, for existing stormwater sewer drainage systems, the number of SUs, their location and size, and orifice size. An SA algorithm, the heuristic method developed for solving the model, has also been described. The hydrologic and hydraulic behavior of the drainage system is assessed using SWMM. A computer program was developed to implement the optimization model and the SA algorithm.

The effectiveness of the proposed model was demonstrated for a case study inspired by a real urban area network, to show its application potential. Different weighting values to penalize flooding were tested to systematically show the tradeoffs between implementing SUs and allowing a certain amount of flooding. As expected, when more SUs are allowed the available storage capacity increases, and more branches of the network can be served. Thus, total and local flooding are both reduced. However, there is a maximum flooding reduction for the available capacities of SUs, and after a certain total volume of SUs, large volume increments result in small flooding reductions. The network changes for different situations were analyzed in detail by considering a set of five different examples, including limitations on total flooding and maximum local flooding volumes. The results showed that large reductions in flooding can be obtained either by restricting flooding limits or through weighting in the objective function, useful when flooding limits are difficult to be established. In addition, factors such as the branch where SUs are located, their size within the available capacities and the diameter of their orifices have a great impact on flooding reduction. This model has demonstrated that it can be a powerful tool for decision makers, who can take advantage of the different parameters included, depending on their flooding reduction goals.

This paper has implemented a completely new and innovative optimization model, but there is still room for future development. An alternative formulation of the optimization model could make use of cost functions, when available, for the investment and operation of the infrastructure and flood damage, and this requires much more information. In addition, uncertainty issues can be included in the optimization approach. Indeed, variables related to climate change and urbanization and variables related to cost cannot be estimated without some degree of uncertainty. An uncertainty approach could provide robust solutions that would perform well under all possible scenarios. 


\section{ACKNOWLEDGMENTS}

The authors would like to thank Mexichem, Colombia for supporting this research through the project "Drenaje Urbano y Cambio Climático: hacia los sistemas de alcantarillado del futuro. Fase I", without which the present study could not have been completed.

\section{REFERENCES}

Aarts, E., Korts, J., and Van Laarhoven, P. J. M. (1997) "Simulated annealing", in: Aarts E, Lenstra JK (Eds.), Local search in combinatorial optimization. Wiley, New York, pp 91-120

Andrade, L. N., Mauri, G. R., and Mendonça, A. S. F. (2013). "General multiobjective model and simulated annealing algorithm for waste-load allocation." Journal of Water Resources Planning and Management, 139(3), 339-344.

Andrés-Doménech, I., Montanari, A., and Marco, J. (2012). "Efficiency of Storm Detention Tanks for Urban Drainage Systems under Climate Variability." Journal of Water Resources Planning and Management, 138(1), 36-46.

Artita, K. S., Kaini, P., and Nicklow, J. W. (2013). “Examining the Possibilities: Generating Alternative Watershed-Scale BMP Designs with Evolutionary Algorithms." Water resources management, 27(11), 3849-3863.

Baek, H., Ryu, J., Oh, J., and Kim, TH (2015). “Optimal design of multi-storage network for combined sewer overflow management using a diversity-guided, cyclic-networking particle swarm optimizer - A case study in the Gunja subcatchment area, Korea" Expert Systems with Applications, 42(20), 6966-697.

Behera, P. K., Papa, F., and Adams, B. J. (1999). "Optimization of regional storm-water management systems." Journal of Water Resources Planning and Management, 125(2), 107-114.

Bennett, M. S., and Mays, L. W. (1985). “Optimal design of detention and drainage channel systems." Journal of Water Resources Planning and Management, 111(1), 99-112. 
Burger, G., Sitzenfrei, R., Kleidorfer, M., and Rauch, W. (2014). "Parallel flow routing in SWMM 5". Environmental Modelling \& Software, 53, 27-34.

Butler, D., and Davies, J. W. (2011). Urban Drainage, 3rd Edition. CRC Press, London.

Chow, V.T., Maidment, D., and Mays, L. W. (1988). Applied Hydrology, McGraw Hill, Singapure.

Cimorelli, L., Morlando, F., Cozzolino, L., Covelli, C., Della Morte, R., and Pianese, D. (2015). "Optimal Positioning and Sizing of Detention Tanks within Urban Drainage Networks." Journal of Irrigation and Drainage Engineering, 142(1), 04015028.

Cunha, M. C. (1999). “On solving aquifer management problems with simulated annealing algorithms." Water resources management, 13(3), 153-170.

Cunha, M. C., and Sousa, J. (1999). "Water distribution network design optimization: simulated annealing approach." Journal of Water Resources Planning and Management, $125(4), 215-221$.

Dougherty, D. E., and Marryott, R. A. (1991). “Optimal groundwater management: 1. Simulated annealing." Water Resources Research, 27(10), 2493-2508.

Dowsland, K. (1993). "Simulated annealing", in: Reeves, C. R. (Eds.), Modern Heuristic Techniques for Combinatorial Problems. John Wiley \& Sons, New York, NY, USA, 20-69.

Doyle, J. R. (1976). "Efficient Storage of Urban Storm Water Runoff." Proceedings of the Conference on Environmental Modeling and Simulation, Cincinnati, Ohio, USA, 139-143.

Elliott, A. H., and Trowsdale, S. A. (2007). "A review of models for low impact urban stormwater drainage." Environmental modelling \& software, 22(3), 394-405.

Fletcher, T., Shuster, W., Hunt, W., Ashley, R., Butler, D., Arthur, S., Trowsdale, S., Barraud, S., Semadeni-Davies, A., Bertrand-Krajewski, B., Mikkelsen, P., Rivard, G., Uhl, M., Dagenais, D., and Viklander, M. (2015). "SUDS, LID, BMPs, WSUD and more - The evolution and application of terminology surrounding urban drainage." Urban Water Journal, 12(7), 525-542.

Fletcher, T.D., Andrieu, H., and Hamel, P. (2013). "Understanding, management and modelling of urban hydrology and its consequences for receiving waters: A state of the art." Adv. Water Resour., 51, 261-279. 
Gironás, J., Roesner, L. A., Rossman, L. A., and Davis, J. (2010). “A new applications manual for the Storm Water Management Model (SWMM)." Environmental Modelling \& Software, 25(6), 813-814.

Iglesias, P.L., and Martínez, F. J. (2014). "Guía de Manejo Rápido de la Librería de Conexión de SWMM 5", Universidad Politécnica de Valencia, España.

Karamouz, M., and Nazif, S. (2013). "Reliability-Based Flood Management in Urban Watersheds Considering Climate Change Impacts." Journal of Water Resources Planning and Management, 139(5), 520-533.

Karovic, O., and Mays, L. W. (2014). "Sewer System Design Using Simulated Annealing in Excel." Water Resources Management, 28(4), 1157-1171

Kessler, A., and Diskin, H. (1991). "The efficiency function of detention reservoirs in urban drainage systems." Water Resources Research, 27(3), 253-258.

Kirkpatrick, S., Gellatt, C., and Vecchi, M. (1983). "Optimization by simulated annealing." Science, 220(4598), 671-680.

Kirshen, P., Caputo, L., Vogel, R., Mathisen, P., Rosner, A., and Renaud, T. (2014). "Adapting Urban Infrastructure to Climate Change: A Drainage Case Study." Journal of Water Resources Planning and Management, 141(4), 04014064.

Maier, H., Kapelan, Z., Kasprzyk, J., Kollat, J., Matott, L., Cunha, M., Dandy, G., Gibbs, M., Keedwell, E., Marchi, A., Ostfeld, A., Savic, D., Solomatine, D., Vrugt, J., Zecchin, A., Minsker, B., Barbour, E., Kuczera, G., Pasha, F., Castelletti, A., Giuliani, M., and Reed, P. (2014). "Evolutionary algorithms and other metaheuristics in water resources: current status, research challenges and future directions." Environmental Modelling \& Software, 62, 271-299.

Marques, J., Cunha, M., and Savić, D. A. (2015). "Multi-objective optimization of water distribution systems based on a real options approach." Environmental Modelling \& Software, 63, 1-13.

Mays, L. W., and Bedient, P. B. (1982). "Model for optimal size and location of detention." Journal of Water Resources Planning and Management, 108(3), 270-285. 
McEnery, J. A., and Morris, C. D. (2012). "Muskingum optimisation used for evaluation of regionalised stormwater detention." Journal of Flood Risk Management, 5(1), 49-61.

Michalewicz, Z., and Fogel, D. B. (2004). How to solve it: Modern heuristics, Springer, Berlin, Germany.

Nix, S. J., and Heaney, J. P. (1988). "Optimization of storm water storage-release strategies." Water Resources Research, 24(11), 1831-1838,

Oxley, R. L., and Mays, L. W. (2014). “Optimization - Simulation Model for Detention Basin System Design." Water Resources Management, 28(4), 1157-1171.

Palumbo, A., Cimorelli, L., Covelli, C., Cozzolino, L., Mucherino, C., and Pianese, D. (2014). "Optimal design of urban drainage networks." Civil Engineering and Environmental Systems, 31(1), 79-96.

Papa, F., and Adams, B. J. (1997). "Application of derived probability and dynamic programming techniques to planning regional stormwater management systems." Water Sci. Technol., 36(5), 227-234.

Park, M., Chung, G., Yoo, C., and Kim, J. H. (2012). “Optimal design of stormwater detention basin using the genetic algorithm." KSCE Journal of Civil Engineering, 16(4), 660-666.

Perez-Pedini, C., Limbrunner, J. F., and Vogel, R. M. (2005). “Optimal location of infiltrationbased best management practices for storm water management." Journal of Water Resources Planning and Management, 131(6), 441-448.

Rathnam, E. V., Abdulla, S. M., and Jayakumar, K. V. (2002). "Urban Runoff Estimation and Optimization of Stormwater Detention Systems-A Case Study for Hyderabad City, India." Bridges, 10(40644), 43.

Rossman, L. (2010). Storm Water Management Model User's Manual, Version 5.0. Cincinnati: National Risk Management Research Laboratory, Office of Research and Development, US-EPA.

Rothlauf, F. (2011). Design of modern heuristics: principles and application. Springer Science \& Business Media, Berlin.

Segarra. R. I. (1995). "Optimal design of runoff storage/release systems." Water Sci Technol, 32(1), 193-199. 
Shamsudin, S., Dan'azumib, S., Aris, A., and Yusop, Z. (2014). "Optimum combination of pond volume and outlet capacity of a stormwater detention pond using particle swarm optimization." Urban Water J., 11(2), 127-136.

Travis, Q., and Mays, L. W. (2008). "Optimizing Retention Basin Networks." Journal of Water Resources Planning and Management, 134(5), 432-439.

Woods-Ballard, B., Kellagher, R., Martin, P., Jefferies, C., Bray, R., and Shaffer, P. (2007). The SUDS Manual C697. London, CIRIA.

Yazdi, J., and Neyshabouri, S. S. (2012). "Optimal design of flood-control multi-reservoir system on a watershed scale." Natural hazards, 63(2), 629-646.

Yeh, C. H., and Labadie, J. W. (1997). "Multiobjective watershed-level planning of storm water detention systems." Journal of Water Resources Planning and Management, 123(6), 336-343.

Zeferino, J. A., Antunes, A. P., and Cunha, M. C. (2009). “An efficient simulated annealing algorithm for regional wastewater system planning." Computer-Aided Civil and Infrastructure Engineering, 24(5), 359-370.

Zhen, X. Y., Yu, S. L., and Lin, J.-Y. (2004). "Optimal location and sizing of stormwater basins at watershed scale." Journal of Water Resources Planning and Management, 130(4), 339347.

Zimmer, A., Schmidt, A., Ostfeld, A., and Minsker, B. (2015). "Evolutionary algorithm enhancement for model predictive control and real-time decision support." Environmental Modelling \& Software, $69,330-341$

Zoppou, C. (2001) "Review of urban storm water models", Environmental modelling \& software, 16, 195-231. 